\title{
and efficiency of
}

the informal

caregivers'

\section{coping strategies}

By Gemma Aucoin-Gallant

\begin{abstract}
This study highlights the coping strategies used by informal caregivers whose husbands live with cancer. It also aims at measuring the efficiency of the selected strategies. The convenience sample was composed of 30 informal caregivers. The results indicate that informal caregivers primarily use support, optimism, independence, and facing of the situation. In general, the categories of coping strategies most often used by informal caregivers are considered by them to be the most efficient. The results of the study encourage nurses to identify more regularly the coping strategies used by informal caregivers; to recognize their efficiency and implement interventions likely to improve the informal caregivers' stress management.
\end{abstract}

In the current health care context, people with cancer remain in their natural environment as much as possible (Adams, 1991; Fitzgerald, 1999). Even though these patients may benefit from some community-based support services, the fact remains that women bear important responsibilities in the care they provide to their husbands. These women are referred to as informal caregivers (Garand \& Bolduc, 1990). While performing their familial, professional, and social functions, women must deal with their informal caregiver roles (Aucoin, 1998). The coping process takes place in the context of this unusual situation. Coping refers to the person's ability to deal with a stressful situation (Fitzgerald). Coping strategies include what informal caregivers think and do when faced with a stressful situation. Thus, the wives develop strategies to come to terms with their feelings and try to overcome an unexpected situation.

The vast majority of studies conducted with informal caregivers show that they need to receive psychological support (Aucoin, 1998). The published literature offers very little information on the strategies used by informal caregivers whose husbands have cancer. Also, no study assessed the efficiency of the coping strategies used by this population. For Lazarus and Folkman (1984), coping strategies are efficient as long as they help the person reduce or manage their stress. The purpose of this investigation was to describe the coping strategies used by informal caregivers, and to also assess the efficiency of the chosen strategies in order to understand the spousal experience throughout this stressful situation. With an improved knowledge of the coping strategies used by informal caregivers, nurses can initiate and implement interventions likely to help the informal caregivers manage their stress.

\section{Investigation purpose and questions}

The purpose of this study was to describe the coping strategies used by informal caregivers whose husbands are living with cancer. It also assessed the efficiency of the coping strategies used by this population. The research questions were as follows:

1. What are the coping strategies used by informal caregivers whose husbands are living with cancer?

2. Do informal caregivers use more problem-focused coping strategies than emotion-focused ones?

3. What coping strategies are rated as most efficient by informal caregivers whose husbands have cancer?

\section{Conceptual framework}

The conceptual framework created by Lazarus and Folkman (1984) provided the theoretical foundation for this study. According to Lazarus and Folkman, coping represents the sum of strategies a person adopts in order to deal with life's stressful situations. In their work, Lazarus and Folkman consider coping strategies as the cognitive and behavioural efforts produced by an individual to react to the demands of his or her environment that are seen as exceeding his or her current resources. Lazarus and Folkman believe that the person assesses the significance of the stressor in relation to his or her well-being. First an assessment is made as to whether the event is irrelevant, harmless, positive, or stressful. During this primary evaluation, the person determines the presence or absence of stress. If the event is perceived in a stressful way, it may be seen as a loss, a threat, or a challenge. Perceptions of loss or threat usually generate anxiety, fear, and concern. As for challenge, it may represent a gain for the person or at least an opportunity to adequately manage the stressful situation.

Then the person assesses the resources and available options to deal with the event, as well as those which are best suited to the situation. The person also reassesses the event. This new evaluation is based on new signs emanating from the environment and on the strategies used to deal with the situation. Lazarus and Folkman specify that for a given event reassessing helps to understand the efficiency of the interaction between the selected coping strategies and the environment. In their publications, they describe two main types of coping strategies: emotion-focused and problem-focused. Generally speaking, emotion-focused coping strategies are more likely to be used if the person believes that nothing can change his or her current situation. On the other hand, if the person thinks that the stressful conditions may be modified, it is very likely that their coping strategies will be focused around the problem (Lazarus \& Folkman). These authors indicate that the two types of coping strategies are usually used simultaneously.

\section{Methodology}

This descriptive study was conducted with 30 informal caregivers whose husbands had been living with cancer for six to 12 months, either in stable condition or undergoing chemotherapy or radiation treatment. The sample was chosen through convenience sampling. The subjects were free to participate or not in the study and they signed a consent form. Data collection took place at the residences of the informal caregivers at times convenient to them. The data were gathered via a single at-home interview which lasted 40 minutes on average. A socio-demographic data form and the Jalowiec Coping Scale (1987) were used. Killeen (1990) and Gulick (1995) report that Jalowiec's instrument is consistent with Lazarus and Folkman's coping theory (1984). According to these authors, the opinions of Jalowiec and Lazarus and Folkman are similar as they indicate the same two main types of coping strategies: one focused on emotions

Gemma Aucoin-Gallant, RN, PhD, is an associate professor at the Centre universitaire de Moncton, Moncton, New Brunswick. 
and one centred on the problem. The researcher observes that the Jalowiec Coping Scale is the only instrument that measures the efficiency of the coping strategies used by the subjects. The instrument's internal consistency was measured using Cronbach's alpha co-efficients of 0.88 for identifying coping strategies and 0.81 for their efficiency.

\section{Findings}

The first research question was phased as follows: "What are the coping strategies used by informal caregivers whose husbands are living with cancer?" To get an answer to this question, informal caregivers were invited to indicate on a scale of 0 to 3 the level of use for each of the 60 coping strategies listed in Jalowiec's instrument (1987). Table One illustrates the means and standard deviations for the eight categories of coping strategies. Based on the informal caregivers' perceptions, the three categories of most frequently used strategies were the following: support $(\mathrm{M}=2.61)$, optimism $(\mathrm{M}=2.51)$ and independence $(M=2.11)$. One should note that the use level for each of these coping strategies ranges from "never used" $(0)$ to "often used" (3). "Expression of emotions" ( $M=1.17)$ "avoidance" ( $M=1.09)$ and "fatalism" $(\mathrm{M}=0.67)$ are the three categories of coping strategies informal caregivers use the least. As one can see in Table One, coping strategy categories are of two types: problem-focused and emotionfocused.

In addition to identifying the categories of coping strategies used the most by the subjects, it is necessary to describe those most frequently used at the time of data collection. Informal caregivers choose to talk about their problem with family members or their friends. It is the most commonly used coping strategy to deal with their current situation and it belongs to the support category. According to informal caregivers, talking about their situation, about cancer for example, provides mutual support to family members and assists them in overcoming the event. Informal caregivers try to keep their situation under control, lead as normal a life as possible, and maintain positive thoughts. By resorting to these three strategies, informal caregivers rely on their support and demonstrate their ability to face the situation and show optimism. Informal caregivers are hoping things will improve and entertain positive thoughts. Table Two illustrates the 10 coping strategies most often used by informal caregivers whose husbands have cancer. It also indicates the categories to which each of these coping strategies belongs. For example, praying and counting on others for help belong to the support category.

The second research question asked: "Do informal caregivers use more problem-focused coping strategies than emotion-focused ones?" . Student's t-test was used to answer this question. The means

\begin{tabular}{|c|c|c|}
\hline \multicolumn{3}{|c|}{$\begin{array}{l}\text { Table One: Utilization of coping strategy categories by } \\
\text { informal caregivers: Means } \\
N=30\end{array}$} \\
\hline $\begin{array}{l}\text { Classification of coping } \\
\text { strategy categories }\end{array}$ & Mean & $\begin{array}{l}\text { Utilization } \\
\text { Standard Deviation }\end{array}$ \\
\hline 1. Support* & 2.61 & 0.28 \\
\hline 2. Optimism** & 2.51 & 0.16 \\
\hline 3. Independence** & 2.11 & 0.23 \\
\hline 4. Facing the situation* & 2.02 & 0.19 \\
\hline 5. Palliative coping** & 1.51 & 0.26 \\
\hline 6. Expression of emotions** & 1.17 & 0.21 \\
\hline 7. Avoidance*** & 1.09 & 0.17 \\
\hline 8. Fatalism** & 0.67 & 0.22 \\
\hline \multicolumn{3}{|c|}{$\begin{array}{l}\text { * Problem-focused coping strategy category } \\
\text { ** Emotion-focused coping strategy category }\end{array}$} \\
\hline \multicolumn{3}{|c|}{ Possible scores ranged from 0 to 3 . } \\
\hline
\end{tabular}

were calculated for both groups. The sample yielded a significant difference between the use of problem-focused and emotion-focused coping strategies. It was found that informal caregivers rely more on problem-focused strategies relative to emotion-focused ones.

The third research question read thus: "What coping strategies are rated as most efficient by informal caregivers whose husbands have cancer?" To answer this question, informal caregivers indicated, on a scale of 0 to 3 , the level of efficiency for each of the coping strategies they used. Table Three presents means and standard deviations for the efficiency of the eight categories of coping strategies. The results show that support, optimism, and facing the situation are the three most efficient categories of coping strategies for the research subjects. On the other hand, avoidance, expression of emotions and fatalism are the three categories perceived as the most inefficient by informal caregivers. It is interesting to note that informal caregivers rated problem-focused strategies as efficient. Overall, the categories of coping strategies most often used by informal caregivers were also perceived by them as the most efficient.

\section{Interpretation of data}

The results of our study indicate that informal caregivers use both strategies focusing on the problem and those focusing on emotions. This recourse to both types of strategies was mentioned in the work of Lazarus and Folkman (1984) and that of Killeen (1990). In this study, informal caregivers drew on a variety of coping strategies, which may lead one to suppose they are going through a stressful situation. It is worth remembering that coping logically succeeds stress. After having assessed the situation as stressful, the caregivers use coping strategies to lessen or manage their stress. Even though informal caregivers are living through a difficult situation, those who rely on different forms of coping strategies are at a lesser risk of developing emotional vulnerability (Miller, 1990). Thus they are demonstrating flexibility in their coping process (Lazarus \& Folkman).

Support is the coping strategy category that informal caregivers utilize the most. They share their concerns and anxieties with relatives and friends. By opening up to others and revealing their feelings, they reduce tension and create solidarity that promotes a state of

Table Two: The 10 most frequently used coping strategies among informal caregivers

$\mathrm{N}=30$

\begin{tabular}{|c|c|c|}
\hline Rank & Strategy & Category \\
\hline First & You discussed your problem & Sunnort* \\
\hline Second & $\begin{array}{l}\text { You tried to keep the situation } \\
\text { under control }\end{array}$ & Facing* \\
\hline Third & $\begin{array}{l}\text { You maintained as normal a life } \\
\text { as possible by not letting the } \\
\text { problem intimidate you }\end{array}$ & Optimism** \\
\hline Fourth & $\begin{array}{l}\text { You tried entertaining } \\
\text { positive thoughts }\end{array}$ & Optimism** \\
\hline Fifth & You wished for things to get better & Optimism** \\
\hline Sixth & $\begin{array}{l}\text { You remembered how you had } \\
\text { solved other problems in the past }\end{array}$ & Independence** \\
\hline Seventh & $\begin{array}{l}\text { You prayed and put your } \\
\text { trust in God }\end{array}$ & Support* \\
\hline Eighth & You counted on others to help you & Support * \\
\hline Ninth & You tried to control your emotions & Independence** \\
\hline Tenth & You worried about the problem & $\begin{array}{l}\text { Expression } \\
\text { of emotions** }\end{array}$ \\
\hline \multicolumn{3}{|c|}{$\begin{array}{l}\text { * Problem-focused coping strategy category } \\
\text { * Emotion-focused coping strategy category }\end{array}$} \\
\hline
\end{tabular}


psychological wellness (Weisman, 1977). In case of need, informal caregivers can also count on a reliable and accessible social network. To mitigate tensions linked to the disease, Lieberman (1982) believes that accessibility is a more important notion than the actual use of the resources offered by the social network. In the literature related to this topic, a consensus seems to emerge that the coping strategy of support is often used and is efficient in helping people deal with the diseaserelated sources of stress (Jalowiec, 1993).

The results confirm that informal caregivers display an optimistic attitude in the face of their stressful situation. In this instance, they appear resistant to pessimistic ideas regarding their spouses' disease. Being and remaining optimistic when faced with a disease were reported by Jalowiec (1993). Concentrating on the positive side of the situation promotes the acceptance of the disease by restructuring the experience to give it meaning (Watson, 1985). Patterson (1989) mentions that people who remain optimistic in the face of a stressful situation demonstrate an open mind, active engagement, and the use of a variety of coping strategies. Lazarus and Folkman (1984) believe that the use of optimistic strategies may facilitate the subsequent use of problem-focused strategies.

Among the groups of coping strategies used by the subjects, independence came in third place. It is evident that informal caregivers rely on past experiences to better deal with their situation. This finding reflects the work of Lazarus and Folkman (1984) who stated that adults draw from their past experience to better come to grips with the problems of everyday life. Thus, the adult experience represents a valuable resource in the use of coping strategies (Lazarus, 1991). The study shows that informal caregivers make an effort to manage their feelings. Controlling one's emotions is interpreted by Jalowiec (1993) as a way of maintaining one's independence in the face of a difficult situation linked to a disease.

It is interesting to note that informal caregivers use more problemfocused strategies than emotion-focused ones. According to Lazarus and Folkman (1984), problem-focused coping strategies are more frequently used in stressful situations related to work. However, when dealing with a chronic health problem, people think they cannot change the source of stress. Therefore they tend to choose emotion-focused strategies. Beaulieu (1993) stresses that people use more problemfocused coping strategies when a stressful situation involves a task to be completed. In the investigation, informal caregivers cared for spouses with cancer. This indeed is a task to be performed. It is likely that caring for one's husband becomes a priority as a stressful situation when compared to the cancer itself. Even though the nature of the event, c.g. disease or work, has an impact on the coping strategies, one should not conclude that it is the only influencing factor.

Table Three: Efficiency of coping strategy categories used by informal caregivers: Means

$\mathrm{N}=30$

\begin{tabular}{|l|c|c|}
\hline $\begin{array}{l}\text { Classification of coping } \\
\text { strategy categories }\end{array}$ & Mean & $\begin{array}{l}\text { Efficiency } \\
\text { Standard deviation }\end{array}$ \\
\hline 1. Support* & 2.72 & 0.21 \\
2. Optimism** & 2.53 & 0.12 \\
3. Independence** & 2.43 & 0.21 \\
4. Facing the situation* & 2.13 & 0.28 \\
5. Palliative coping** & 2.11 & 0.22 \\
6. Expression of emotions*** & 1.43 & 0.21 \\
7. Avoidance** & 0.73 & 0.23 \\
8. Fatalism** & 0.67 & 0.21 \\
\hline
\end{tabular}

* Problem-focused coping strategy category

** Emotion-focused coping strategy category

To obtain the means for the utilization of coping strategies, the rank was o to 3.
When it comes to the efficiency of coping strategies, it is worth remembering that the subjects were assessed selectively, i.e. through a single interview. However, one can group these strategies as being of a high efficiency, medium efficiency, or low efficiency. In the study, the most efficient strategy categories are support, optimism, and facing of the situation. These results are close to those reported by Weisman (1977) who thinks that the person who endeavours to objectively examine a problem tends to be more successful in the analysis. This gives meaning to the event and incorporates it gradually into everyday life. Then the person seeks out positive elements from the situation. The individual calls upon the support of family members, friends, and their own religious beliefs. Still according to Weisman, these strategies are the most efficient to adapt to a stressful situation related to cancer.

According to the study subjects, independence and positive compensation strategies, referred to as positive palliative coping, are considered as being of medium efficiency. Jalowiec (1993) emphasizes that, by controlling their emotions and relying on their previous experience, people can be more independent in their actions. While positive compensation strategies, such as diversion, are not problem-centred, this type of strategy promotes emotion control (Lazarus \& Folkman, 1984). For Jalowiec, independence and positive palliative coping are considered to be adequately efficient by people experiencing stress linked to a disease.

Avoidance, expression of emotions and fatalism are among the strategies that informal caregivers rated as less efficient. These results agree with the ideas put forward by Weisman (1977). This author concludes that people who deny reality, who blame others and who, through fatalism, resign themselves to the situation, are using nonefficient strategies to cope with a situation related to cancer. However, Lazarus and Folkman (1984) think that temporary denial may be valuable at the onset of the disease. At that time, people have few resources available to them to focus their strategies on the problem. Denial allows them to diminish their emotional reaction to the situation.

\section{Conclusion}

This study demonstrates that informal caregivers adopt problemfocused coping strategies more frequently as opposed to emotionfocused ones. It emphasizes that informal caregivers use mostly support, optimism, independence, and facing of the situation. It may well be that the support and optimism together allow informal caregivers to better deal with the situation. It is interesting to observe that, in general, the categories of coping most often used by informal caregivers are also viewed by them as being the most efficient. Nowadays, in the early part of 2001 , nurses should be able to implement an evaluation and reinforcement process for coping strategies. This will allow them to identify the coping strategies being used, to recognize their level of efficiency, and to develop interventions aimed at helping the caregivers to better manage their stress.

This investigation's limitations are worth mentioning. The study utilized a convenience sample. Therefore, the results are limited to the sample under consideration and their generalization is impossible. Coping strategies were assessed on an ad hoc basis, i.e. through a single interview. As coping constitutes a process, the identified strategies have a rather limited scope. One can wonder if most of the coping strategies vary significantly over time. Longitudinal studies with adults experiencing stressful situations related to cancer would help paint a more comprehensive picture of their usual coping strategies. Other studies could analyze the nature of the relationships between optimism, support, and facing the situation. Correlational studies could explore the relationships between a stressful event, the socio-demographic variables in adults, and the use of coping strategies. 


\section{References}

Adams, M. (1991). Information and education across the phases of cancer care. Seminars in Oncology Nursing, 7(2), $105-$ 111.

Aucoin, G. (1998). Les besoins d'apprentissage et les stratégies de «coping" de la soignante naturelle. Thèse doctorale inédite. Montréal: Université de Montréal.

Beaulieu, D. (1993). Description du stress et des stratégies de «coping» chez les infirmières en soins prolongés. Mémoire de maîtrise inédit. Montréal: Université de Montréal.

Fitzgerald, M. (1999). Coping with chronic illness: Overcoming powerlessness. Philadelphia: F.A. Davis.

Garand, L., \& Bolduc, M. (1990). L'aide par les proches. Québec: Ministère de la santé et des services sociaux.

Gulick, E.E. (1995). Coping among spouses or significant others of persons with multiple sclerosis. Nursing Research, 44(4), 220-225.

Jalowiec, A. (1987). Jalowiec Coping Scale. Unpublished manuscript. Chicago: University of Illinois.

Jalowiec, A. (1993). Coping with illness: Synthesis and critique of nursing coping literature from 1980-1990. In J. Barnfather \& B. Lyons (Eds.), Stress and coping: State of the science and implications for nursing theory, research and practice (pp. 65-83). Indianapolis: Sigma Theta Tau Press.

Killeen, M. (1990). The influence of stress and coping on family caregivers' perception of health. International Journal of Aging and Human Development, 30(3), 197-211.

Lazarus, R.S. (1991). Emotion and adaptation. New York: Oxford University Press.

Lazarus, R.S., \& Folkman, S. (1984). Stress, appraisal, and coping. New York: Springer.

Lieberman, M.A. (1982). The effects of social support on responses to stress. In L. Goldberg \& S. Brenitz (Eds.), Handbook of stress: Theorical and clinical aspects (pp. 5376). New York: Free Press.

Miller, C.A. (1990). Nursing care of older adults. Glenview: Scott, Foresman.

Patterson, B.H. (1989). Creativity and andragogy: A boon for adult learners. Journal of Creative Behavior, 20(2), 99-109.

Watson, J. (1985). Nursing: Human science and human care. Norwalk: Appleton-Century-Crofts.

Weisman, A.D. (1977). Coping with cancer. New York: McGraw-Hill. 